\title{
How does parental personality influence offspring quality in animals?
}

\author{
A. Chira
}

Chira A., 2014. How does parental personality influence offspring quality in animals? Ann. For. Res. 57(2): 347-362, 2014.

Abstract. Behaviour ecology has become a popular research area, and its importance in understanding the evolution, ecology and diversity of life on Earth is now fully recognised. More recently, consistent differences between individuals (including personality traits) have become the target of animal studies, and such differences have been reported in a wide range of invertebrate and vertebrate taxa. The study of animal personality has expanded in the last decade, and it now benefits from a clear theoretical framework, supported by empirical evidence. Many studies report that personality traits influence individual fitness, but it is not clear how and why this happens. The present review explores this gap in the current knowledge and provides a comprehensive perspective of the main arguments put forward to explain why individuals' personality traits influence their fitness. Specifically, I investigate (a) how is personality associated with life-history and reproductive investment, (b) how personality traits can represent the basis of mate choice, and what are the implications of assortative mating based on personality, and (c) how personality can impact the amplitude and outcomes of intra-familial conflicts. Additionally, I aim to identify the main knowledge gaps on the subject and provide some general guidelines for future theoretical and empirical work, and also briefly highlight the broad impacts that personality research has for evolutionary biology and ecology, as well as for applied conservation. Keywords personality, reproductive investment, life-history, assortative mating, family interactions.

Authors. Angela Chira (boa10amc@sheffield.ac.uk) - University of Sheffield, Animal and Plant Sciences Department Western Bank, Sheffield, South Yorkshire S10 2TN, United Kingdom.

Manuscript received March 27, 2014; revised October 03, 2014; accepted October 13, 2014; online first October 17, 2014. 


\section{Introduction}

Behavioural ecology and the birth of personality research. Behavioural ecology describes the evolutionary basis of animal behaviour i.e. it investigates how and why behaviours are maintained by Darwinian selection (Alcock 2009). This area of Biology was born in the 1940s, with the pioneer works of Niko Tinbergen, Konrad Lorenz \& Karl von Frisch. Descriptions and interpretations of animal behaviour exist since Antiquity; however, it was these three researchers who structured the study of behaviour as a systematic research area, with core hypotheses and predictions, tested by experiments and/or correlational studies.

Behavioural ecology generally aims at answering four main questions about animal behaviour, as postulated by Niko Tinbergen: (i) what is the underlying mechanism of behaviour?, (ii) how does behaviour develop?, (iii) what is the current function of behaviour?, and (iv) what is the evolutionary history of behaviour?. Central interdependent themes within behavioural ecology include: the study of reproductive behaviour and sexual selection (mating systems, courtship behaviour, sperm competition), the study of sociality (group living, cooperation between and within species, altruistic behaviour, mutualism), the study of communication between animals (signals, mimicry, deceit), as well as the study of family interactions, migration, feeding behaviour, brood parasitism etc, virtually any type of behaviour animals show (Alcock 2009) At present, behavioural ecology is a fully established area of research, with a multitude of papers being published annually in high profile biological journals.

More recently, a new area of research within behavioural ecology has risen: the study of animal personality i.e. the study of differences in behaviour between individuals that are consistent in time and across contexts (Dall et al.2004, Reale et al.2007, Smith \& Blumstein 2008).
Variability in individual behaviour has been repeatedly reported since the 1970 s, however, such differences were in general interpreted as noise in the data (Dall et al.2004, Reale et al. 2007, Schuett et al. 2010). The systematic investigation of personality started in the 2000 s, following a few studies that established the basic ideas in the 1990s (e.g. Verbeek et al. 1994, Godin \& Dugatkin 1996, Budaev et al. 1999).

The concept of a personality trait is described by two key points: high inter-individual and low-intra-individual variation in behaviour (Schuett et al. 2010); that is, individuals clearly differ between each other but are consistent in their behaviours across contexts and in time. Reale et al. (2007) defined five main personality traits: boldness (individual inclination to take risks), exploration (individual affinity to explore new environments), activity, aggressiveness (individual antagonistic behaviour directed towards conspecifics), and sociability (individual inclination to engage in social interactions). The field of personality research has been pronged by semantic arguments over terminology, some of which are outlined in Box 1. In recent years, however, a general consensus in terminology and on the methods used for measuring personality traits has emerged, (Box 2, Reale et al. 2007), which means personality research benefits now from an established conceptual framework.

Personality research so far: influences on individual fitness. Personality traits have been studied in relation to a wide range of functional contexts (Table 1), and have further been correlated with multiple fitness measurements (see notable lists of such studies in Reale et al. 2007, Schuett et al. 2010) and life-history traits (e.g. growth, onset of reproduction, age at sexual maturity, etc. reviewed by Biro \& Stamps 2008).

A recent meta-analysis of personality studies reveals that bold individuals have more offspring, but reduced survival compared to shy ones. Exploration scores weakly correlate with survival and aggression has a small positive ef- 


\section{Box 1. Terminology}

There are a multitude of terms authors use as synonyms to personality: behavioural type (Sih et al. 2004a, Sih et al. 2012), behaviour axis, personality dimension (Smith \& Blumstein 2008), temperament, coping style (Reale et al. 2007), and behavioural syndrome. The term temperament, however, is mostly used in anthropomorphic studies. Also, coping style is generally avoided, as it rather describes a behavioural strategy to a specific set of conditions, and not a singular personality trait (Sih et al. 2004a).

Behavioural syndrome (BS) is a more complicated term that still creates much confusion, and different authors use it in different contexts. Sometimes, a BS is used to describe the same idea as personality - a correlation between individual behaviour across functional contexts (Sih et al. 2004a,b, Smith \& Blumstein 2008, Dall et al. 2012). In this paper, however, I will use a BS to express a correlation between personality traits (sensu Dingemanse \& Reale 2005, Sih \& Bell 2008); e.g. bolder individuals are more aggressive too. Stamps \& Groothius (2010) detail this definition by noting that a BS defines correlations between behaviours in time OR across functional contexts, whereas a personality trait refers to behaviours correlated across temporal AND functional contexts.

Individuals express their personality traits while foraging, feeding their young or mating - and these have been defined as functional contexts or domains ( $\mathrm{Sih}$ et al. 2004b, Reale et al. 2007, Schuett et al. 2008, Dall et al. 2012). A situation represents the general current conditions in which an individual expresses its personality traits (e.g. breeding/non-breeding season, or current food levels; Sih et al. 2004b).

fect on both survival and reproductive success (Smith \& Blumstein 2008). The authors used data extracted from 31 papers in which naturalistic observations, coding of behaviour and rating were used to quantify personality traits sensu Reale et al. (2007). The meta-analysis compiles results from studies on arthropods, fish, birds, and mammals, showing that personality traits are not trivial, rather they can have important implications for the ecology and evolution of a wide range of species (Dall et al. 2012).

So far, personality has been linked with fitness measurements such as: individual survival (e.g. Dugatkin 1992), individual ability to respond to environmental fluctuations (e.g.

\section{Box 2. Methods for measuring personality}

Since the definitions of the five main personality traits have been universally accepted (Reale et al. 2007), a general agreement on the methods used to quantify personality has emerged quickly. Variation in methodology still exists because of obvious differences in the study systems (for example wild versus laboratory studies); however, authors now have a clear understanding of what they are measuring, which makes methodology standard across studies.

Exploratory behaviour is universally quantified using by the open field test, which quantifies the response of individuals when introduced to a novel environment. For example in birds, exploratory behaviour is generally measured by introducing individuals into an aviary with artificial trees (an unexplored environment). Exploration scores are established based on: number of trees birds sample, number of hops and flights while on a particular tree, time spent on a tree before moving forward, etc. (e.g. Groothius \& Carere 2004).

Aggression (i.e. antagonistic response to conspecifics) involves quantifying individual responses to: (i) its own image in a mirror (standard test; Figure 1b, (ii) real or models of conspecifics, (iii) play-back calls.

The standard boldness (response to risk) measurement is to quantify individual response to a novel object introduced in its environment. Variations to this test include replacing the object with a model/real predator, playback calls of predators, a human intruder, etc.

Dingemanse et al. 2004), fertilization success (e.g. Sinn et al. 2006, Ariyomo \& Watt 2012), brood size (e.g. Kontiainen et al. 2009), offspring weight at birth (e.g. Both et al. 2005, Stapley \& Keogh 2005), offspring survival to and quality at independence (e.g. Reale et al. 2000, Sinn et al. 2006, Schuett et al. 2011b), and finally recruitment (e.g. Dingemanse et al. 2004, Kontiainen et al. 2009). These studies have contributed to the growing evidence that personality affects fitness; the processes through which these effects are mediated are, however, a matter of continuing debate. Given that comprehensive reviews on the links between personality and fitness are only a few years old, it is not surprising that the mecha- 


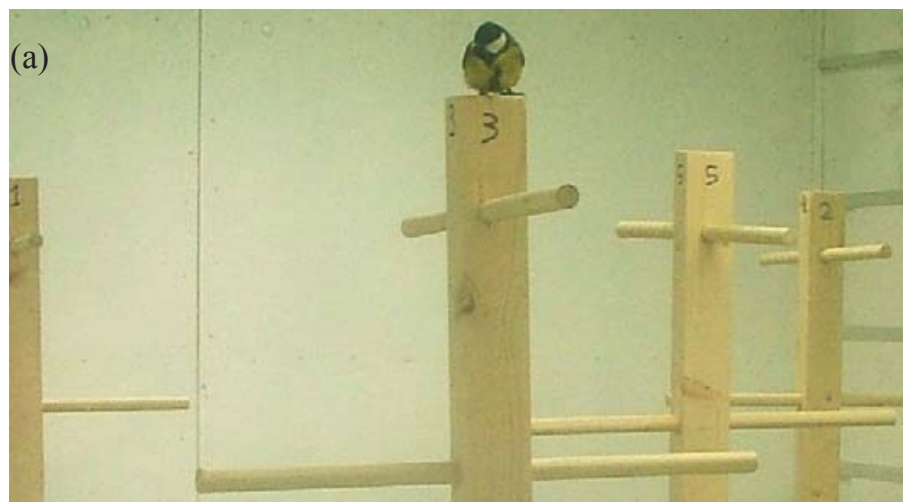

(b)

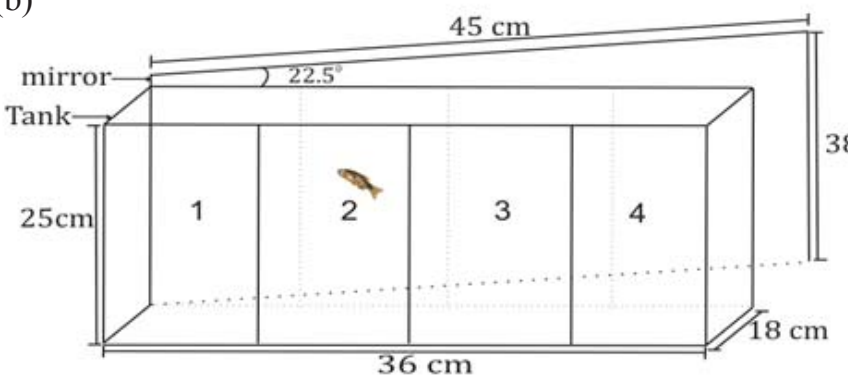

Figure 1 (a) Exploratory behaviour of bird species is generally measured by introducing individuals into an aviary with artificial trees (an unexplored environment). Exploration scores are established based on: number of trees birds sample, number of hops and flights while on a particular tree, time spent on a tree before moving forward, etc. (e.g. Groothius \& Carere, 2004; picture from Max-Planck Institute website; http://tinyurl. com/ptnvwsk). (b) Schematic representations of the mirror test used to measure aggression in the zebrafish (Danio rerio; Ariyomo, 2013). The fish is introduced into a tank with a mirror placed on one side. Because the mirror is placed at an angle, the fish perceives its image (a potential adversary) as being further away as it moves from tank sections 1 to 4 . Aggression scores are determined by the number of bites, and displays directed to the mirror image, and the fish's preference to stay 'closer' (tanks 1 or 2 ) or 'further' away (tanks 3 and 4 ) from its image. (drawing by T. Ariyomo; from Ariyomo, 2013).

Table 1 Examples of how personality traits are expressed in various functional contexts

\begin{tabular}{|c|c|}
\hline Functional context & Expression of personality traits \\
\hline Foraging & $\begin{array}{l}\text { Explorers travel further while searching for food compared to non-explorative } \\
\text { individuals (great tits, Parus major; van Oerveld \& Mathyssen 2010). }\end{array}$ \\
\hline Dominance & $\begin{array}{l}\text { Boldness correlates with dominance hierarchies within shoals (zebrafish, Danio } \\
\text { rerio, Dahlbom et al. 2011). } \\
\text { Exploration correlates with dominance over food resources during the non-breeding } \\
\text { season (great tits; Both et al. 2005). }\end{array}$ \\
\hline \multicolumn{2}{|r|}{ les secure best territories (great tits, Both et al. 2005) } \\
\hline Female preference & $\begin{array}{l}\text { Females prefer bold males to shy ones (guppies, Poecilia reticulata; Godin \& } \\
\text { Dugatkin 1996). } \\
\text { Explorative females prefer explorative males (zebra finches, Taeniopygia guttata; } \\
\text { Schuett et al. 2011a). }\end{array}$ \\
\hline Parental care & $\begin{array}{l}\text { Aggressive individuals provide little for their brood (bluebirds, Sialia mexicana; } \\
\text { Duckworth 2006). }\end{array}$ \\
\hline Nest defence & $\begin{array}{l}\text { Aggressive individuals invest heavily in nest defence (convict cichlids, Cichlasoma } \\
\text { (Archocentrus) nigrofasciatum; Budaev et al. 1999). }\end{array}$ \\
\hline Dispersal & $\begin{array}{l}\text { Explorative individuals disperse further than non-explorers (great tits; Dingemanse } \\
\text { et al. 2003). }\end{array}$ \\
\hline Sociality & $\begin{array}{l}\text { Boldness correlates with the tendency to shoal (European wrasse, Symphodus } \\
\text { ocellatus; Budaev 1997). } \\
\text { Slow explorers form long-term associations with few individuals, whereas fast } \\
\text { explorers engage in short-term interactions with many conspecifics (great tits; Aplin } \\
\text { et al. 2013) }\end{array}$ \\
\hline
\end{tabular}


nisms underlying such links are not well understood.

Study aims. The current paper reviews the main theoretical and empirical findings that explain the relationship between personality and offspring quality as a measure of parental fitness, highlighting the progress made so far in this field.

Firstly, I will investigate the hypothesis that personality influences fitness via its potential effect on reproductive investment (the life-history theory; Wolf et al. 2007). Parental care involves a series of interdependent behaviours, all related to some extent to personality traits. I attempt to analyse how personality links with each element in the network, and further investigate how these links interact to explain the observed correlations between personality and fitness (Figure 2).

Secondly, I will investigate an alternative hypothesis through which personality can influence offspring fitness: assortative mating based on personality traits. Assortative mating theory implies that small differences between parental personalities positively affect offspring quality. Finally, I will briefly discuss how personality traits can affect family interactions, specifically how certain combinations of personality scores between the members of the family can decrease intra-familial conflicts,

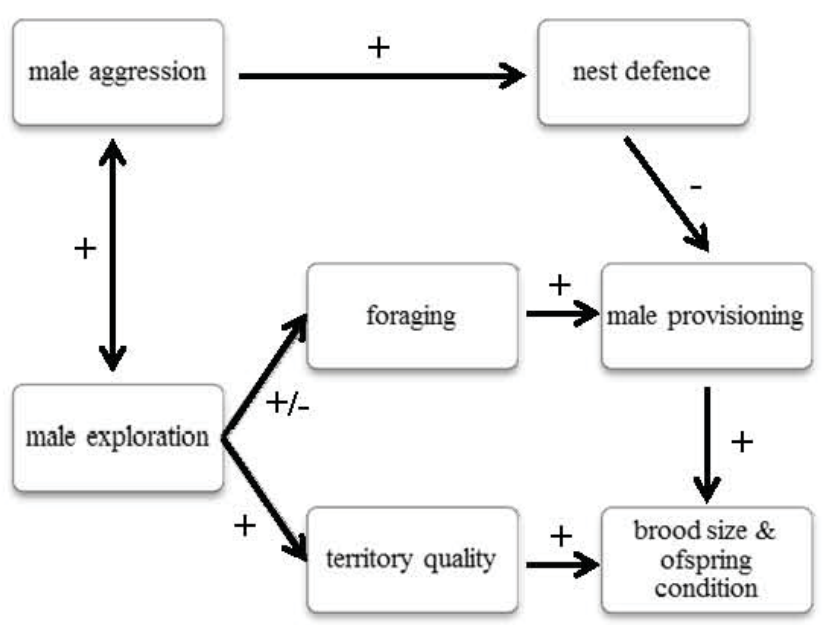

and thus increase fitness of offspring. This area has received little attention so far, but the existing theoretical arguments show good potential for further work.

By the end of this review, I hope to have highlighted three potential mechanisms by which personality influences fitness: (i) personality of each parent guides its reproductive investment strategy, (ii) differences in personality scores between members of a pair influence the efficiency of parental care, and (iii) specific combinations of personality scores mediate family conflict. By bringing together the theoretical arguments and the patchy supporting evidence existing so far, I hope to have created a general framework on which future empirical work can develop. Another aim of this paper is to suggest where and what type of future work is needed in order to develop a better understanding of the mechanisms linking personality to fitness.

\section{Personality and reproductive investment}

On average, $35 \%$ of the variation observed in individual behaviour is caused by consistent differences between individuals (Bell et al. 2009). Often, however, the expression of personality traits is too subtle to be observed, or

Figure 2 Schematic representation of a multi-pathway approach to quantifying how exploration influences on parental care and fitness. Exploration affects provisioning indirectly because of its links with (i) aggression and nest defence (negative feedback), and (ii) foraging (direction of feedback is situation dependent). Exploration can also impact provisioning directly - high explorative individuals are expected to invest heavily in their current brood (positive feedback; Wolf et al. 2007). The direct and indirect pathways further feedback on offspring condition. Based on arguments from: Both et al. 2005, Hollander et al. 2007, Mutzel et al. 2013). 
masked by more powerful forces driving behaviour (e.g. individual's current energy levels). What are then the functional contexts in which we expect personality to make a notable impact on how an individual responds? Could personality be important in contexts related to reproductive investment?

\section{The life-history hypothesis - personality links with reproductive investment}

Personality traits describe how individuals respond to novelty or risk (Reale et al. 2007). Particularly, high levels of activity, exploration, boldness, aggression and sociability are closely associated with the idea of being riskprone i.e. ready to jump into risky situations like exploring an unknown, potentially dangerous environment, or engaging in social interactions with unfamiliar individuals (Pike et al. 2008). Individual response to risk is also the central concept behind a well-known life-history trade-off: investment into current versus future reproduction. Risk-prone individuals (sometimes called Type A) adopt a high-risk high-reward strategy, putting maximum efforts in the current breeding event and potentially compromising their own survival. Conversely, Type B individuals have many, smaller payoffs reproduction events in their life-time (a low risk, low reward strategy; Bennet \& Owens 2002, Reale et al. 2010).

Drawing an analogy between life-history trade-offs and personality based on the common concept of risk allowed several authors to elaborate the life-history theory regarding personality (Stamps 2007, Wolf et al. 2007, Biro \& Stamps 2008, Reale et al. 2010). A core hypothesis is that high levels of boldness, exploration, aggressiveness, sociability, and activity associate with heavy investment in current reproduction. Therefore, based on the life-history theory, we expect personality traits to be highly relevant in the context of reproductive investment, and consequently, have a notable impact on individual fitness. Further, the prediction is that bold, aggressive, explorative, 352 active, extrovert individuals make the most out of every breeding event i.e. they get best territories, start breeding early, maximise levels of parental care (especially provisioning), and invest heavily in nest building and defence (Wolf et al. 2007).

So far, most studies focused on the relationship between personality and two important functional contexts related to the breeding attempt: nest defence and provisioning (Table 2). As it can be seen from the summarising table, the influence of personality on reproductive investment follows some general directions, some in contradiction and some in agreement with the life-history theory.

\section{Personality and nest defence}

Nest defence is a key form of reproductive investment, and it can play an important role in offspring survival (e.g. Blancher 1982, Weidinger 2002, Andersson \& Waldeck 2006). Nests can be threatened by predators, conspecifics, or other intruders such as humans, which the pair tries to chase away by attacking directly, giving alarm calls, performing displays to distract predators, etc. (e.g. Hendrichsen et al. 2006, Carillo \& Aparicio 2008, Randler 2013). Several studies report that over $50 \%$ of variation in nest defence seen in wild populations is explained by consistent differences between individuals i.e. personality (Kontiainen et al. 2009, Betini \& Norris 2011, Burtka and Grindstaff 2013). Further, as predicted by the lifehistory theory, aggressiveness and exploration scores have been found to correlate positively with nest defence in several species (Table 2a). Such findings show that personality traits do influence the amount of effort individuals invest in defending their nest; moreover, this relationship drives variation in recruitment (and implicitly offspring quality) between individuals in some cases (Kontiainen et al. 2009, Betini \& Norris 2011). 
Table 2 Examples of empirical studies investigating the impact of personality traits on (a) nest defence* and (b) provisioning. Positive / negative correlations between personality traits and the functional contexts of interest are indicated by a "+" or "“-" sign, respectively; "0" means that no correlation between personality and defence/provisioning has found

(a) Nest defence

\begin{tabular}{llll}
\hline \multirow{2}{*}{ Species } & \multicolumn{2}{l}{ Personality } & \\
\cline { 2 - 3 } & \multicolumn{2}{l}{ Aggressiveness Exploration } & References \\
\cline { 2 - 3 } Great tits (Parus major) & & + & Hollander et al. 2008 \\
Convict cichlids (Cichlasoma nigrofasciatum) & + & & Budaev et al. 1999 \\
Bluebirds (Sialia mexicana) & + & Duckworth 2006 \\
\hline
\end{tabular}

(b) Provisioning

\begin{tabular}{|c|c|c|c|c|c|c|c|}
\hline \multirow{3}{*}{ Species } & \multicolumn{6}{|c|}{ Personality } & \multirow{3}{*}{ References } \\
\hline & \multicolumn{2}{|c|}{ Aggressiveness } & \multicolumn{2}{|c|}{ Boldness } & \multicolumn{2}{|c|}{ Exploration } & \\
\hline & Males & Fem & Males & Fem & Males & Fem & \\
\hline $\begin{array}{l}\text { Convict cichlids (Cichlasoma } \\
\text { nigrofasciatum) }\end{array}$ & - & - & + & + & + & + & Budaev et al. 1999 \\
\hline Blue tits (Cyanistes caeruleus) & - & & & & 0 & + & Mutzel et al. 2013 \\
\hline Bluebirds (Sialia mexicana) & - & & 0 & & & & Duckworth 2006 \\
\hline House wrens (Troglodytes aedon) & - & & 0 & & & & Barnett et al. 2012 \\
\hline Great tits (Parus major) & & & & & 0 & 0 & Patrick \& Browning 2011 \\
\hline House mice (Mus domesticus) & & + & & & & & Benus \& Röndigs 1996 \\
\hline Ural owls (Strix uralensis) & & + & & & & & Kontiainen et al. 2009 \\
\hline
\end{tabular}

\section{Personality and provisioning}

Provisioning is a key form of parental care, and it directly influences offspring condition (e.g. Hager and Johnstone 2006, Schwagmeyer and Mock 2008). As is the case with nest defence, a significant proportion of the variation in provisioning is caused by repeatable, consistent differences between individuals (Westneat et al. 2011), which supports the prediction that personality traits influence parental investment. So far, provisioning has been studied in relation to exploration, aggressiveness, and boldness.

Aggressiveness and provisioning. The relationship between aggression and parental care is a well-studied topic in behavioural ecology; however, only the more recent studies interpret and quantify aggression following the terminology and standard methods established within the modern personality framework (Box1; Box 2). As it has been reported in the past, recent personality studies show that, in most cases, aggressiveness correlates negatively with levels of provisioning (Table 2b). These findings are rather intuitive. Individuals cannot maximise all aspects of reproductive investment, so trade-offs usually exist between the efforts directed to various investment contexts (Bennet \& Owens 2002). Aggression is a measure of combat abilities, so it makes sense for aggressive individuals to invest heavily in defence, minimizing provisioning rates (Markman et al. 1995). The negative feedback ag- 
gressiveness has on provisioning is mainly mediated via hormonal pathways; generally, aggressive individuals have high testosterone levels, a hormone which decreases affiliation to young and parental care levels (the so called T-mediated trade-off; e.g. McGlothlin et al. 2007, Rodgers et al. 2013). All in all, aggressiveness has a considerable negative impact on provisioning. Further, the aggression-provisioning relationship has been found to impact offspring condition, either negatively (because of decreased parental care; Duckworth 2006) or positively (because the partner overcompensates; Mutzel et al. 2013).

Exploration and provisioning. The link between exploration and provisioning has only been recently dealt with, and in general, studies report weak or no correlations between explorative behaviour and provisioning (Table $2 b)$. However, exploration does affect several contexts linked with provisioning (notably foraging, dispersal, and territory acquisition). Because of these relationships, exploration is thought to feedback indirectly on parental care, an argument (so far, an untested hypothesis) authors use to explain why exploration correlates with offspring condition in several studies (e.g. Both et al. 2005, Schuett et al. 2011b, Gabriel \& Black 2012).

Several correlational studies (especially on great tits) report that exploration is closely linked with foraging strategies. Slow explorative individuals are thorough foragers (Verbeek et al. 1994); whereas fast explorers quickly sample many food sources, which they exploit superficially (Herborn et al. 2010). When a faced with a decrease in food supplies, explorative individuals more rapidly try finding new food sources, and they travel further to find them compared to non-explorers (van Oerveld \& Mathyssen 2010); explorers would also readily go into a dangerous environment to access a potential good food patch (Quinn et al. 2012). Further, fast explorers more rapidly form feeding routines than slow explorers (Herborn et al. 2010). Therefore, fast explor- ers adopt a high reward - high risk strategy while foraging, as predicted by the life-history theory. Fast explorers also disperse far (Dingemanse et al. 2003), and male explorers tend to find and secure good quality territories (Both et al. 2005).

Based on the observed correlations mentioned previously, a set of predictions have been elaborated regarding exploration and fitness. In good years, fast explorers are expected to do best - they can get hold of territories with abundant resources that they exploit quickly, which allows them provide for their young at a fast pace. In poor years, however, resources and good territories are rare. Slow explorers should be at an advantage then, as their thorough foraging strategy allows them to find the scarce food sources, and then exploit them until depletion (Both et al. 2005, Patrick \& Browning 2011, Mutzel et al. 2013). These lines of reasoning are supported by empirical data: generally, fast explorers recruit more offspring than slow ones in good years, but the reverse is true in poor year (Dingemanse et al. 2004). Also, slow explorative females do better compared to fast ones on poor territories (Schuett et al. 2011b). Therefore, exploration behaviour is linked with the ability to secure and exploit food sources, which naturally feedbacks on the amount of resources parents can provide to their offspring i.e. the quality of parental care, and consequently on offspring quality. There are, however, several factors that complicate these links, namely the trade-off between provisioning and defence or the distribution of food resources; also offspring themselves have a say in determining provisioning rates (Box 3).

To sum up, as predicted by the theory, personality is greatly expressed in contexts related to the breeding attempt. Personality traits affect (i) how much resources individuals invest in the current reproduction event (the life-history theory), and (ii) the ability of individuals to provide good parental care (exploration in particular because of its links with foraging suc- 
cess and territory acquisition). Further, these relationships explain (to some extent at least) the differences in fitness in terms of offspring condition and recruitment between individuals at the opposite ends of each personality trait spectrum.

\section{Assortative mating based on personality traits}

Personality traits affect individual reproductive investment, but they can also influence fitness by acting at the level of the pair; specifically, assortative mating based on personality traits can positively influence offspring condition.

In behavioural ecology, assortative mating describes a situation in which individuals choose mates that are similar to them to the detriment of dissimilar individuals, even if the latter are of better quality (Burley 1983, Jiag et al. 2013). Individuals can choose a mate of similar morphology to them (e.g. Pryke \& Griffith 2007, Bortolotti et al. 2008, Martin, 2013), or behaviour (e.g. Bearhop et al. 2005). Mating assortatively is beneficial if: (i) similarity at the genetic level gives offspring an advantage, and/or (ii) similarity in behaviour between parents increases the efficiency of mating and/or parental care. If such benefits are higher than the costs of mating with a lower quality partner, assortative mating is adaptive (Schuett et al. 2010). Several studies show that assortative mating based on personality exists (e.g. Schuett et al. 2011a, Kralj-Fišer et al. 2013), and moreover, pairs similar in personality have a fitness advantage in terms of increased fertilization success (e.g. Sinn et al. 2006), offspring size (e.g. Both et al. 2005, Stapley \& Keogh 2006, Schuett et al. 2011b), offspring numbers (e.g. Budaev et al. 1999, Ariyomo \& Watt 2013), and fledgling success (e.g. Gabriel \& Black 2012).

\section{Assortative mating increases the compatibil- ity of the pair}

What makes personality-assorted pairs more successful than dissimilar ones? So far, the literature supports hypothesis (ii) i.e. assorted pairs do not offer their offspring superior gene combinations; rather they provide good parental care for their young. The most elegant proof for this argument comes from a study on zebra finches. In these species, pairs similar in their exploration scores raise better offspring than dissimilar pairs; a cross-fostering experiment showed that all variance in offspring quality is explained by personality differences between foster parents and not genetic ones (Schuett et

\section{Box 3. Why isn't exploration more obviously linked with provisioning?}

Exploration correlates with aggression and boldness (Verbeek et al. 1994, Budaev et al. 1999, Herborn et al. 2010, Hyman et al. 2013), and it thus becomes important in the context of nest defence (see section 2.1.). Therefore, as in the case with aggression, the trade-off between care and defence weakens a potential positive correlation between exploration and provisioning (especially in males; Mutzel et al. 2013). Furthermore, the role of exploration in determining foraging success depends on other various factors, such as the distribution of resources (e.g. in a system with clumped food sources fast explorers might always do best because they can monopolise and defend patches of food; Patrick \& Browning 2011), or the direction of selection (as discussed above).
The link between individual personality and provisioning also comes with an additional complication: offspring influence provisioning rates via their begging behaviour. Personality traits can be expressed at very early stages in life, including the dependent stage (Roulin et al. 2010); in great tits, for example, more explorative young have higher begging rates (Carere et al. 2005). Therefore, when correlating parental personality with provisioning, studies must account for brood size, sex and age of young, etc., but also for the personality of offspring - a potential confounding variable that has not been included in studies so far. Young personality usually associates with parental traits, as personality is determined by a combination between genes (Drentet al. 2003, Ariyomo \& Watt 2013) and the rearing environment (Carere et al. 2005, Schuett et al. 2013) 
al. 2011b). As shown in previous sections, individual personality is linked with finding a territory, foraging, provisioning, and nest defence. It makes sense, thus, to assume that individuals similar in their personality scores will also behave similarly in the functional contexts above-mentioned. The argument is that such similarities cause a high behavioural compatibility between partners, which is known to increase the efficiency of parental care and, consequently, offspring quality (Box 4).

Does similarity in personality traits between partners increase the compatibility of the pair? Assorted steller jays (Cyanocitta stelleri) pairs nest earlier than dissimilar pairs, potentially because individuals similar in their boldness and exploration scores share the same strategy while looking for a territory and nest site, which speeds the onset of breeding (Gabriel \& Black, 2013). Also, convict cichlids pairs similar in their exploration scores have similar provisioning rates (correlative data; Budaev et al. 1999). When studying such relationships an important detail must not be overlooked: are the partners similar in behaviour prior pairforming, or do they become more compatible

\section{Box 4. Behavioural compatibility}

Behavioural compatibility describes the extent to which members of a pair accord in various functional contexts (e.g. copulation, finding a territory, building a nest, and further incubating the eggs and taking care of young; Spoon et al. 2006)

High behavioural compatibility increases the success of the breeding pair, hypothesis supported by empirical evidence (Ryan \& Altmann 2001, Gleason et al. 2012). In cockatiels (Nymphicus hollandicus) for example, high compatibility - quantified as low aggression levels between partners, large amounts of time spent in close proximity of each other, frequent copulations, allopreening and other affiliative behaviours - correlate with an increase in the number of chicks raised to independence, and a decrease in the probability of extra pair copulations and divorce (Spoon et al. 2007); also behavioural synchrony during incubation increases the chances of laying eggs and hatching success (Spoon et al. 2006). In many bird species, high percentages of synchrony in nest visits - also a measure of pair compatibility - increase brood size and fledgling percentages (e.g. Mariette \& Griffith 2012, van Rooij \& Griffith 2013). as a result of spending time together? So far, evidence shows that the levels of behavioural compatibility and similarity in personality scores between mates do not increase with time, which means individuals mate assortatively from the start (Spoon et al. 2006, Gabriel \& Black 2013, but see Griggio \& Hoi 2011 for contrasting conclusions). Clearly, assortative mating based on personality is a subject with knowledge gaps still. However, plenty predictions and verbal arguments have already been put forward (e.g. Figure 3), and it should be only a matter of time until empirical evidence will catch up with theoretical ideas.

\section{Assortative mating based on consistency; personality and family interactions}

Personality traits are characterised by low intra-individual variation, or consistency (Schuett et al. 2010). Assortative mating based on the consistency of personality traits has only been shown in zebra finches, a species in which individuals choose partners with similar inter-individual variation levels in exploratory behaviour (Schuett et al. 2011a), and pairs with the same consistency in exploration have the fittest offspring (Schuett et al. 2011b).

Fairly new theories relate the idea of consistency with the resolution of inter-sexual conflict. The consistency of personality traits is thought to signal how predictable an individual is in various functional contexts, including parental care (Dall et al. 2004, Schuett et al. 2010). Highly consistent individuals are likely to be trustworthy and cooperate in parental effort, whereas an inconsistent individual is likely to exploit its partner or even desert the brood (Royle et al., 2010). It makes sense, thus, for individuals to choose a partner similar in consistency to them in order to avoid being exploited; as a consequence, parental conflict can be decreased by mating assortatively based on consistency (Royle et al. 2010). Such hypotheses represent scope for further work, as no empirical studies so far have looked at how 


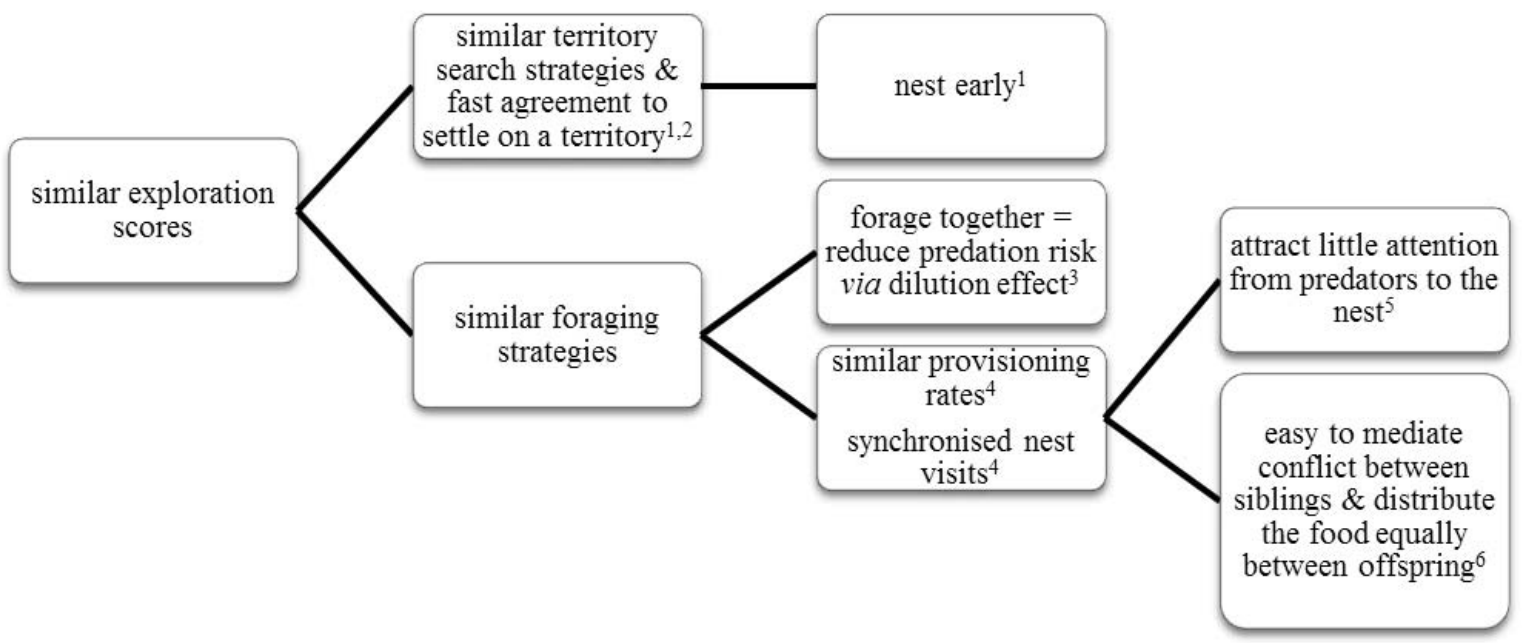

Figure 3Potential pathways via which similarity in a personality trait (here explorative behaviour) can lead to high behavioural compatibility between partners and further benefit the pair. Based on arguments from: Gabriel \& Black 2012, Stamps et al. 2002, Mariette \& Griffith 2012, Royle et al. 2010, Raihani et al. 2010, Shen et al. 2010

personality influences individual response to changes in its partner parental investment (but see Patrick \& Browning, 2001, for a first step in exploring these matters: this study showed that great tits increase their provisioning rates when offspring demands are enhanced, but the rates of change are not different between fast and slow explorers).

A few authors have started studying the role of personality within families (e.g. Roulin et al. 2010). These concepts are at a very incipient stage, but already several verbal arguments have been put forward. Firstly, as discussed above, personality traits influence cooperation between mates, and can also mediate the conflict between the sexes. Secondly, personality traits are expressed very in life i.e. even at a dependent stage (Carere et al. 2005), so it makes sense that personality also acts on parent-offspring conflict and sibling competition. An interesting idea is that offspring can more easily adopt an efficient strategy to maximise parental care if parents have similar personalities i.e. parents share the same parental care strategy (Roulin et al. 2010). This hypothesis already received some support from studies showing that assorted pairs raise high quality offspring (discussed previously). Exciting further work includes modelling the fitness pay-offs of various combinations of parental and offspring personalities in order to obtain the evolutionary stable strategies. The expectation is that selection will favour specific combinations of personality traits within families, depending on the parental care system the species of interest exhibit, local conditions and direction of selection, etc. (Roulin et al. 2010).

Personality beyond behavioural ecology. The implications of personality traits on ecology and evolution are now starting to receive attention (Dall et al. 2012). First of all, personality has received attention from evolutionary ecologists (Dingemanse \& Wolf 2013). For example, the existence of fixed differences in behaviour between individuals contradicts fundamental ideas regarding the flexibility and adaptability of behaviours (e.g. Wolf \& Weissing, 2010). In addition, personality is studied in relation to individual niche specialisation, division of labour and stability in social groups (Bergmuller et al. 2010, Carter et al. 2014). Secondly, personality impacts on the ecology 
of populations. For example, explorative behaviour is known to associate with dispersal abilities (e.g. Dingemanse et al. 2003), and ultimately with the capacity of individuals to colonise new habitats (e.g. Brodin et al. 2013). Following similar arguments, personality has been linked with the outcome of intra/interspecific competition or predator-prey interactions, and therefore with population dynamics, species abundance, speciation, and ecological displacements (see Sih et al. 2012 review). Thirdly, personality is considered when dealing with conservation issues. Behavioural types associate with the idea of coping with risk and novelty, which naturally links with individual ability to adapt in the face of urbanisation and climate change (Sih et al. 2012). Moreover, personality affects fitness and (as the present review highlights) offspring quality, therefore it is not surprising that conservation programmes have started to take notice at such behavioural parameters for the rehabilitation of greatly endangered species.

\section{Conclusions}

Personality traits have become a self-contained, influential subject in behavioural ecology. Correlations between personality and fitness have already been reported by many studies, and we are now beginning to understand the underlying mechanisms behind such relationships. Personality acts both at the individual and the pair level. Firstly, differences in personality explain a significant part of the variation seen in reproductive investment between individuals. Secondly, assortative mating based on personality increases the behavioural compatibility between partners, and consequently the efficiency of parental care. Lastly, personality traits alleviate intra-familial conflicts, and they can influence the outcome of family interactions.

There are many gaps in our current understanding of animal personality. For example, personality has never been studied in relation to nest building - a key form of reproductive investment and a functional context where high compatibility between partners could be advantageous (for example, highly compatible partners could potentially build their nest fast). The big advantage of studying the expression of personality traits at this stage of the breeding attempt is the absence of offspring. With no young, the results are not complicated by the additional feedback loops offspring have on parental care (see Box 3). The subject of assortative mating based on personality also requires future comprehensive studies that will (i) estimate the personality of partners before and after the pair is formed, (ii) estimate the influence of individual personality on various forms of reproductive investment, (iii) correlate the similarity in personality between mates with the behavioural compatibility of the pair, and (iv) relate compatibility with offspring success.

As knowledge in the subject grows, probably more variation in behaviour that has been left unexplained until the present will be attributed to personality traits. Personality research also opens doors for new ideas; particularly, the role of personality traits within families promises many opportunities for theoretical and empirical further work.

\section{References}

Alcock J., 2009. Animal Behaviour ( $9^{\text {th }}$ ed.). Sunderland, Massachusetts, Sinauer Associates.

Andersson M., Waldeck P., 2006. Reproductive tactics under severe egg predation: an eider's dilemma. Oecologia 148(2): 350-355. DOI: 10.1007/s00442-006-0374-7.

Aplin L.M., Farine D.R., Morand-Ferron J., Cole E.F., Cockburn A., Sheldon B.C., 2013. Individual personalities predict social behaviour in wild networks of great tits (Parus major). Ecology letters 16(11): 1365-1372. DOI: $10.1111 /$ ele.12181.

Ariyomo T.O., Watt P., 2012. The effect of variation in boldness and aggressiveness on the reproductive success of zebrafish. Animal Behaviour 83(1): 41-46. DOI: 10.1016/j.anbehav.2011.10.004.

Ariyomo T.O., 2013. Personality traits of the zebrafish, Danio rerio, and the guppy, Poecilia reticulate. $\mathrm{PhD}$ 
thesis.

Ariyomo T.O, Watt P.J., 2013. Disassortative mating for boldness decreases reproductive success in the guppy. Behavioral Ecology 24(6): 1320-1326. DOI: 10.1093/ beheco/art070.

Ariyomo T.O., Carter M., Watt P.J., 2013. Heritability of Boldness and Aggressiveness in the Zebrafish. Behavior Genetics 43(2): 161-167. DOI: 10.1007/s10519013-9585-y.

Bearhop S., Fiedler W., Furness R.W., Votier S.C., Waldron S., Newton J., Bowen G.J., Berthold P., Farnsworth K., 2005. Assortative mating as a mechanism for rapid evolution of a migratory divide. Science 310(5747): 502504. DOI: $10.1126 /$ science. 1115661 .

Bell A.M., Hankison S.J., Laskowski K.L., 2009. The repeatability of behaviour: a meta-analysis. Animal Behaviour 77(4): 771-783. DOI: 10.1016/ j.anbehav.2008.12.022.

Bennett P.M., Owens I.P., 2002. Patterns of covariation between life-history traits. In: Bennett P.M., Owens I.P. Evolutionary ecology of birds. Oxford: Oxford University Press, pp. 34-49.

Benus R.F., Röndigs M., 1996. Patterns of maternal effort in mouse lines bidirectionally selected for aggression. Animal Behaviour 51(1): 67-75. DOI: 10.1006/ anbe.1996.0006.

Bergmüller R., Schürch R., Hamilton I.M., 2010. Evolutionary causes and consequences of consistent individual variation in cooperative behaviour. Philosophical Transactions of the Royal Society B: Biological Sciences 365: 2751-2764.

Betini G.S., Norris D.R., 2012. The relationship between personality and plasticity in tree swallow aggression and the consequences for reproductive success. Animal Behaviour 83(1): 137-143.

Biro P.A., Stamps J.A., 2008. Are animal personality traits linked to life-history productivity? Trends in Ecology and Evolution 23(7): 361-368. DOI: 10.1006/ anbe.1996.0006.

Blancher P.J., Robertson R.J., 1982. Kingbird aggression: does it deter predation? Animal Behaviour 30(3): 929930. DOI: 10.1016/S0003-3472(82)80167-X.

Bortolotti G.R., González L.M., Margalida A., Sánchez R., Oria J., 2008. Positive assortative pairing by plumage colour in Spanish imperial eagles. Behavioural processes 78(1): 100-107. DOI: 10.1016/j.beproc.2008.01.007.

Both C., Dingemanse N.J., Drent P.J., Tinbergen J.M., 2005. Pairs of extreme avian personalities have highest reproductive success. Journal of Animal Ecology 74(4): 667-674. DOI: 10.1111/j.1365-2656.2005. 00962.x.

Brodin T., Lind M.I., Wiberg M.K., Johansson F., 2013. Personality trait differences between mainland and island populations in the common frog (Ranatemporaria). Behavioral Ecology and Sociobiology 67(1): 135143. DOI: $10.1007 / \mathrm{s} 00265-012-1433-1$.

Budaev S.V., 1997. Alternative styles in the European wrasse, Symphodus ocellatus: boldness-related schooling tendency. Environmental Biology of Fishes 49(1):
71-78. DOI: 10.1023/A: 1007380212475.

Budaev S.V., Zworykin D.D., Mochek A.D., 1999. Individual differences in parental care and behaviour profile in the convict cichlid: a correlation study. Animal Behaviour 58(1): 195-202. DOI: 10.1006/ anbe.1999.1124.

Burley N., 1983. The meaning of assortative mating. Ethology and Sociobiology 4(4): 191-203. DOI: 10.1016/0162-3095(83)90009-2.

Burtka J.L., Grindstaff J.L., 2013. Repeatable nest defense behavior in a wild population of Eastern bluebirds ( $\mathrm{Si}$ alia sialis) as evidence of personality. Acta Ethologica 16(3): 135-146. DOI: 10.1007/s10211-013-0143-7.

Carere C., Drent P.J., Koolhaas J.M., Groothuis T.G., 2005. Epigenetic effects on personality traits: early food provisioning and sibling competition. Behaviour 142(910): 1329-1356. DOI: $10.1163 / 156853905774539328$.

Carrillo J., Aparicio J.M., 2001. Nest defence behaviour of the Eurasian Kestrel (Falco tinnunculus) against human predators. Ethology 107(10): 865-875. DOI: 10.1046/ j.1439-0310.2001.00718.x.

Carter A.J., English S., Clutton-Brock T.H., 2014. Cooperative personalities and social niche specialization in female meerkats. Journal of Evolutionary Biology 27(5): 815-825. DOI: 10 . 1111/jeb. 12358 .

Dahlbom S.J., Lagman D., Lundstedt-Enkel K., Sundström L.F., Winberg S., 2011. Boldness predicts social status in zebrafish (Danio rerio). PloS One 6(8): 1-7. DOI: 10.1371/journal.pone.0023565.

Dall S.R., Houston A.I., McNamara J.M., 2004. The behavioural ecology of personality: consistent individual differences from an adaptive perspective. Ecology Letters 7(8): 734-739. DOI: $10.1111 /$ j.14610248.2004.00618.x.

Dall S.R., Bell A.M., Bolnick D.I., Ratnieks F.L., 2012. An evolutionary ecology of individual differences. Ecology Letters 15(10): 1189-98. DOI: 10.1111/j.14610248.2012.01846.x.

Dingemanse N.J., Both C., van Noordwijk A.J., Rutten A.L., Drent P.J., 2003. Natal dispersal and personalities in great tits (Parus major). Proceedings of the Royal Society of London. Series B: Biological Sciences 270(1516): 741-747. DOI: 10.1098/rspb.2002.2300.

Dingemanse N.J., Both C., Drent P.J., Tinbergen J.M., 2004. Fitness consequences of avian personalities in a fluctuating environment. ProcBiol Sci. 271(1542): 847-852. DOI: 10.1098/rspb.2004.2680.

Dingemanse N.J., Réale D., 2005. Natural selection and animal personality. Behaviour 142(9-10): 9-10.

Dingemanse N.J. Wolf M., 2013. Between-individual differences in behavioural plasticity within populations: causes and consequences. Animal Behaviour 85(5): 1031-1039. DOI: 10.1016/j.anbehav. 2012.12.032.

Drent P.J., van Oers K., van Noordwijk A.J., 2003. Realized heritability of personalities in the great tit (Parus major). Proceedings of the Royal Society of London. Series B: Biological Sciences 270(1510): 45-51. DOI: 10.1098/rspb.2002.2168.

Duckworth R.A., 2006. Behavioral correlations across 
breeding contexts provide a mechanism for a cost of aggression. Behavioral Ecology 17(6): 1011-1019. DOI: 10.1093/beheco/arl035.

Dugatkin L.A., 1992. Tendency to inspect predators predicts mortality risk in the guppy (Poecilia reticulata). Behavioral Ecology 3(2): 124-127. DOI: 10.1093/beheco/3.2.124.

Gabriel P.O., Black J.M., 2012. Behavioural syndromes, partner compatibility and reproductive performance in Steller's jays. Ethology 118(1): 76-86. DOI: 10.1111/ j.1439-0310.2011.01990.x.

Gabriel P.O., Black J.M., 2013. Correlates and Consequences of the Pair Bond in Steller's Jays. Ethology 119(2): 178-187. DOI: $10.1111 /$ eth.12051.

Gleason E.D., Holschbach M.A., Marler C.A., 2012. Compatibility drives female preference and reproductive success in the monogamous California mouse (Peromyscus californicus) more strongly than male testosterone measures. Hormones and Behavior 61(1): 100-107. DOI: 10.1016/j.yhbeh.2011.10.009.

Godin J.G., Dugatkin L.A., 1996. Female mating preference for bold males in the guppy, Poecilia reticulata. Proceedings of the National Academy of Sciences 93(19): 10262-10267. DOI: 10.1073/pnas. 93.19.10262.

Griggio M., Hoi H., 2011. An experiment on the function of the long-term pair bond period in the socially monogamous bearded reedling. Animal Behaviour 82(6): 1329-1335. DOI: 10.1016/j.anbehav. 2011.09.016.

Groothuis T.G., Carere C., 2005. Avian personalities: characterization and epigenesis. Neuroscience and Biobehavioral Reviews 29(1): 137-150. DOI: 10.1016/ j.neubiorev.2004.06.010.

Hager R., Johnstone R.A., 2006. The influence of phenotypic and genetic effects on maternal provisioning and offspring weight gain in mice. Biology Letters 2(1): 8184. DOI: $10.1098 / \mathrm{rsbl} .2005 .0403$.

Herborn K.A., Macleod R., Miles W.T., Schofield A.N., Alexander L., Arnold K.E., 2010. Personality in captivity reflects personality in the wild. Animal Behaviour 79(4): 835-843. DOI: 10.1016/j.anbehav. 2009.12.026.

Hollander F.A., van Overveld T., Tokka I., Matthysen E., 2008. Personality and nest defence in the great tit $(\mathrm{Pa}$ rus major). Ethology 114(4): 405-412. DOI: 10.1111/ j.1439-0310.2008.01488.x.

Hyman J., Myers R., Krippel J., 2013. Personality influences alarm calling behaviour in song sparrows. Behaviour 150(9-10): 1147-1164.

Jiang Y., Bolnick D.I., Kirkpatrick M., 2013. Assortative Mating in Animals. The American Naturalist 181(6): 125-138. DOI: 10.1086/ 670160.

Hendrichsen D.K., Christiansen P., Nielsen E.K., Dabelsteen T., Sunde P., 2006: Exposure affects the risk of an owl being mobbed-experimental evidence. Journal of Avian Biology 37(1): 13-18. DOI: 10.1111/j.2005.09088857.03658.x.

Kontiainen P., Pietiäinen H., Huttunen K., Karell P., Kolunen H., Brommer J.E., 2009. Aggressive Ural owl mothers recruit more offspring. Behavioral Ecol- ogy 20(4): 789-796. DOI: 10.1093/ beheco/arp062.

Kralj-Fišer S., Mostajo G.A.S., Preik O., Pekár S., Schneider J.M., 2013. Assortative mating by aggressiveness type in orb weaving spiders. Behavioral Ecology 24(4): 824-831. DOI: $10.1093 /$ beheco/art030.

Mariette M.M. Griffith S.C., 2012. Nest visit synchrony is high and correlates with reproductive success in the wild Zebra finch Taeniopygiaguttata. Journal of Avian Biology 43(2): 131-140. DOI: 10.1111/j.1600048X.2012.05555.x.

Markman S., Yom-Tov Y., Wright J., 1995. Male parental care in the orange-tufted sunbird: behavioural adjustments in provisioning and nest guarding effort. Animal Behaviour 50(3): 655-669. DOI: 10.1016/ 00033472(95)80127-8.

Martin C.H., 2013. Strong assortative mating by diet, colour, size, and morphology but limited progress toward sympatric speciation in a classic example: Cameroon crater lake cichlids. Evolution 67(7): 2114-2123. DOI: 10.1111/evo.12090

McGlothlin J.W., Jawor J.M., Ketterson E.D., 2007. Natural variation in a testosterone-mediated trade-off between mating effort and parental effort. The American Naturalist 170(6): 864-875. DOI: 10. 1086/522838.

Mutzel A., Dingemanse N.J., Araya-Ajoy Y.G., Kempenaers B., 2013. Parental provisioning behaviour plays a key role in linking personality with reproductive success. Proceedings of the Royal Society B: Biological Sciences 280(1764): 1-9.

Patrick S.C., Browning L.E., 2011. Exploration behaviour is not associated with chick provisioning in great tits. PloS One 6(10): 1-7. DOI: 10.1371/journal. pone.0026383.

Pike T.W., Samanta M., Lindström J., Royle N.J., 2008. Behavioural phenotype affects social interactions in an animal network. Proceedings of the Royal Society B: Biological Sciences 275(1650): 2515-2520. DOI: 10.1098/rspb.2008.0744.

Pryke S.R., Griffith S.C., 2007. The relative role of male vs. female mate choice in maintaining assortative pairing among discrete colour morphs. Journal of Evolutionary Biology 20(4): 1512-1521. DOI: 10.1111/ j.1420-9101.2007.01332.x.

Quinn J.L., Cole E.F., Bates J., Payne R.W., Cresswell W., 2012. Personality predicts individual responsiveness to the risks of starvation and predation. Proceedings of the Royal Society B: Biological Sciences 279(1735): 19191926. DOI: 10.1098/rspb.2011.2227.

Raihani N.J., Nelson-Flower M.J., Moyes K., Browning L.E., Ridley A.R., 2010. Synchronous provisioning increases brood survival in cooperatively breeding pied babblers. Journal of Animal Ecology 79(1): 44-52. DOI: $10.1111 /$ j.1365-2656.2009.01606.x.

Randler C., 2013. Alarm calls of the Cyprus Wheatear Oenanthe cypriaca - one for nest defence, one for parent-offspring communication? Acta Ethologica 16(2): 91-96. DOI: 10.1007/s10211-012-0141-1.

Réale D., Gallant B.Y., Leblanc M., Festa-Bianchet M., 
2000. Consistency of temperament in bighorn ewes and correlates with behaviour and life history. Animal Behaviour 60(5): 589-597. DOI: 10.1006/anbe.2000.1530.

Réale D., Reader S.M., Sol D., McDougall P.T., Dingemanse N.J., 2007. Integrating animal temperament within ecology and evolution. Biological Reviews 82(2): 291-318. DOI: 10.1111/j.1469-185X.2007.00010.x.

Réale D., Garant D., Humphries M.M., Bergeron P., Careau V., Montiglio P.O., 2010. Personality and the emergence of the pace-of-life syndrome concept at the population level. Philosophical Transactions of the Royal Society B: Biological Sciences 365(1560): 4051-4063. DOI: 10.1098/rstb.2010.0208.

Rodgers C., Neff B.D., Knapp R., 2013. Androgen-mediated nurturing and aggressive behaviors during paternal care in bluegill sunfish (Lepomisma crochirus). Hormones and Behavior 63(3): 454-461. DOI: 10.1016/ j.yhbeh.2012.12.008.

Roulin A., Dreiss A.N., Kölliker M., 2010. Evolutionary perspective on the interplay between family life, and parent and offspring personality. Ethology 116(9): 787796.

Royle N.J., Schuett W., Dall S.R., 2010. Behavioral consistency and the resolution of sexual conflict over parental investment. Behavioral Ecology 21(6): 11251130. DOI: 10.1093/beheco/arq156.

Ryan K.K., Altmann J., 2001. Selection for male choice based primarily on mate compatibility in the oldfield mouse, Peromyscus polionotus rhoadsi. Behavioral Ecology and Sociobiology 50(5): 436-440. DOI: 10.1007/s002650100385.

Schuett W., Tregenza T., Dall S.R., 2010. Sexual selection and animal personality. Biological Reviews 85(2): 217 246. DOI: 10.1111/j.1469-185X.2009.00101.x.

Schuett W., Godin J.G.J., Dall S.R., 2011a. Do female zebra finches, Taeniopygia guttata, choose their mates based on their 'personality'? Ethology 117(10): 908917. DOI: 10.1111/j.1439-0310.2011. 01945.x.

Schuett W., Dall S.R.X., Royle N.J., 2011b. Pairs of zebra finches with similar 'personalities' make better parents. Animal Behaviour 81(3): 609-618. DOI: 10.1016/ j.anbehav.2010.12.006.

Schuett W., Dall S.R., Wilson A.J., Royle N.J., 2013. Environmental transmission of a personality trait: foster parent exploration behaviour predicts offspring exploration behaviour in zebra finches. Biology Letters 9(4): 1-6. DOI: $10.1098 /$ rsbl.2013.0120.

Schwagmeyer P.L. Mock D.W., 2008. Parental provisioning and offspring fitness: size matters. Animal Behaviour 75(1): 291-298. DOI: 10.1016/j.anbehav.2007.05.023.

Shen S.F., Chen H.C., Vehrencamp S.L., Yuan H.W., 2010. Group provisioning limits sharing conflict among nestlings in joint-nesting Taiwan yuhinas. Biology Letters 6(3): 318-321. DOI: 10.1098/ rsbl.2009.0909.

Sih A., Bell A. Johnson J.C., 2004a. Behavioral syndromes: an ecological and evolutionary overview. Trends in Ecology and Evolution 19(7): 372-378. DOI: 10.1016/j.tree.2004.04.009.
Sih A., Bell A.M., Johnson J.C., Ziemba R.E., 2004b. Behavioral syndromes: an integrative overview. The Quarterly Review of Biology 79(3): 241-277. DOI: 10.1086/422893.

Sih A. Bell A.M., 2008. Insights for behavioral ecology from behavioral syndromes. Advances in the Study of Behavior 38: 227-281. DOI: 10. 1016/S00653454(08)00005-3.

Sih A., Cote J., Evans M., Fogarty S., Pruitt J., 2012. Ecological implications of behavioural syndromes. Ecology Letters 15(3): 278-289. DOI: $10.1111 / \mathrm{j} .1461$ 0248.2011.01731.x.

Sinn D.L., Apiolaza L.A., Moltschaniwskyi N.A., 2006. Heritability and fitness-related consequences of squid personality trait. Journal of Evolutionary Biology 19(5): 1437-1447. DOI: 10.1111/j.1420-9101.2006.01136.x.

Smith B.R., Blumstein D.T., 2008. Fitness consequences of personality: a meta-analysis. Behavioral Ecology 19(2): 448-455. DOI: 10.1093/beheco/arm144.

Spoon T.R., Millam J.R., Owings D.H., 2006. The importance of mate behavioural compatibility in parenting and reproductive success by cockatiels, Nymphicus hollandicus. Animal Behaviour 71(2): 315-326. DOI: 10.1016/j.anbehav.2005.03.034.

Spoon T.R., Millam J.R., Owings D.H., 2007. Behavioural compatibility, extrapair copulation and mate switching in a socially monogamous parrot. Animal Behaviour 73(5): 815-824. DOI: 10.1016/j.anbehav. 2006.10.010.

Stamps J.A., 2007. Growth-mortality tradeoffs and 'personality traits' in animals. Ecology Letters 10(5): 355363. DOI: 10.1111/j.1461-0248.2007.01034.x.

Stamps J., Groothuis T.G., 2010. The development of animal personality: relevance, concepts and perspectives. Biological Reviews 85(2): 301-325. DOI: 10.1111/ j.1469-185X.2009.00103.x.

Stapley J., Keogh J.S., 2005. Behavioral syndromes influence mating systems: floater pairs of a lizard have heavier offspring. Behavioural Ecology 16(3): 514-520. DOI: 10.1093/beheco/ari019.

van Overveld T., Matthysen E., 2010. Personality predicts spatial responses to food manipulations in free-ranging great tits (Parus major). Biology Letters 6(2): 187-190. DOI: 10.1098/rsbl.2009.0764.

van Rooij E.P., Griffith S.C., 2013. Synchronised provisioning at the nest: parental coordination over care in a socially monogamous species. PeerJ 1(232): 1-14.

Verbeek M.E., Drent P.J., Wiepkema P.R., 1994. Consistent individual differences in early exploratory behaviour of male great tits. Animal Behaviour 48(5): 1113 1121. DOI: 10.1006/anbe.1994.1344.

Weidinger K., 2002. Interactive effects of concealment, parental behaviour and predators on the survival of open passerine nests. Journal of Animal Ecology 71(3): 424-437. DOI: 10.1046/j.1365-2656.2002.00611.x.

Westneat D.F., Hatch M.I., Wetzel D.P., Ensminger A.L., 2011. Individual variation in parental care reaction norms: integration of personality and plasticity. The American Naturalist 178(5): 652-667. DOI: 
$10.1086 / 662173$.

Wolf M., van Doorn G.S., Leimar O., Weissing F.J., 2007. Life-history trade-offs favour the evolution of animal personalities. Nature 447(7144): 581-584. DOI: 10.1038/nature05835.
Wolf M., Weissing, F.J., 2010. An explanatory framework for adaptive personality differences. Philosophical Transactions of the Royal Society B: Biological Sciences 365(1560): 3959-3968. DOI: 10.1098/rstb.2010.0215. 